\title{
IPE-COM: a pilot study on interprofessional learning design for medical and midwifery students
}

This article was published in the following Dove Press journal:

Journal of Multidisciplinary Healthcare

\author{
ABT Randita' \\ W Widyandana ${ }^{2}$ \\ M Claramita $\mathbb{D}^{2}$
}

'Medical Education Unit, Faculty of Medicine, Universitas Sebelas Maret, Surakarta, Indonesia; ${ }^{2}$ Department of Medical, Health Professions Education, and Bioethics, Faculty of Medicine, Public Health and Nursing, Universitas Gadjah Mada, Yogyakarta, Indonesia
Correspondence: ABT Randita Medical Education Unit, Faculty of Medicine, Universitas Sebelas Maret, JI. Ir Sutami No. 36 A Kentingan, Surakarta,

Central Java 57/26, Indonesia

Tel +6282226674919

Email boy.timor@staff.uns.ac.id
Background: The skills of interprofessional teamwork, such as collaboration, team management, and interprofessional communication skills, should be embedded in the early stages of health profession education. In Indonesia, medical doctors and midwives have important roles and often work closely to partnership within the primary health care settings. Therefore, both medical students and midwifery students should have an interprofessional education training together during their professional education, using a community-based learning approach.

Purpose: This study aimed to investigate the effect of a community-based interprofessional educational learning on collaborative competencies (communication, collaboration, roles and responsibilities, collaborative patient-centered approach, the team functioning, and conflict management).

Method: Pre-experimental study with one group pre- and post-test design in 15 medical students and 19 midwifery students were involved in the community-based IPE (IPE-COM) course, later divided into nine groups. Data were collected by direct observations of supervisors using Interprofessional Collaborator Assessment Rubric (ICAR) instrument.

Results: The finding showed significant increase in IPE competencies before and after the 4-week course. IPE community-based learning had the strongest effect on the team's functioning competence, while collaborative patient-centered approach competence had a moderate effect.

Conclusion: IPE community-based learning had positive impact with increasing collaborative competencies for both medical and midwifery students.

Keywords: interprofessional education, community-based learning, medical and midwifery students, interprofessional competencies

\section{Introduction}

The quality of health service is often determined by the concern and responsiveness of care providers to the preferences, needs, and values of patients and consumers, when applying the concept of patient-centered care. To achieve the holistic patientcentered care, health professionals need to be equipped with collaborative competences since the early stage of their health professional education. Collaborative competencies are widely known as Interprofessional Education (IPE), which has the main purposes of patient safety and improved quality of health service. ${ }^{3}$ IPE refers to a common goal among health care providers that can be learned in a shared learning process with the core curriculum coordination. In such learning process, joint decision making and professional accountability will also be nurtured. Moreover, in IPE, each professional discipline maintains shared values, contributes to knowledge sharing, and commits in a joint decision making process with all the disciplines working together. ${ }^{18}$ 
IPE can occur when two or more health professions learn together, learn from each other, and work together in studying the roles of each health profession to improve the collaboration and quality of health service. ${ }^{27}$ However, the implementation of IPE still varies and depends on the policy of institutions, hospitals, and attitudes of students and the community. ${ }^{22}$ One of the variations can be seen in the diverse IPE curriculum and teaching forms. IPE may be taught as short duration courses, or served as student field project tasks, or applied as a "spiral" concept where every year IPE learning is scaffolded as a long-term terraced approach to continued higher education. ${ }^{2,5}$

With the wide range of forms of IPE, the implementation can fundamentally refer to the theory of "Situated learning" and "Community practice". ${ }^{24}$ The second important aspect of the theory involving collaborative learning is interactive learning experiences with direct observation and professional cooperation. ${ }^{3}$ Previous research also emphasized the emergent need for early exposure for collaborative learning, understanding obligations and demands of each professions' roles and responsibilities, and developing of intensive interprofessional communication to achieve the common goals. ${ }^{17}$

In Indonesia, interprofessional collaboration should occur between doctors and midwives in primary care settings. Collaborations could be formed as partnership between midwives (bidan desa), who work closely with a community in a village, and doctors, who serve as a functional health center physician. Recent indicators show that the majority of collaborations occur in health-based community work. ${ }^{15}$ This form of collaboration is mentioned in the rules of the new Indonesian National Universal Health Coverage System, which stipulates that both professions must also collaborate in primary health care settings. National health problems, concerning maternal and neonatal health issues, are the highest priorities in the two professions.

The report of the Millennium Development Goals (MDGs) by the World Health Organization (WHO) revealed that there were 36 neonatal deaths per 1000 births in the region of South East Asia. In Indonesia, the incidence is among the worst, where 40 neonatal deaths were reported in 1000 births. Meanwhile, WHO set the goal in 2015's MDGs as low as 25 neonatal deaths per 1000 births. ${ }^{28}$ Accordingly, the neonatal death per 1000 birth in Indonesia are still high. Data from the Indonesian Ministry of Health in 2013 showed the rates of newborn and maternal mortality as high. The factors that raised a tremendous concern include inadequate health care facilities, lack of informed health workers, and referral systems that did not run well. Collaboration between midwives and doctors continued to be a serious challenge for the government and community agendas that would determine the national health priority issues. ${ }^{16}$

In Universitas Sebelas Maret, one preliminary study supported by national funding resources revealed a set of guidelines of IPE for community-based learning (IPE-COM) from a series of focus group discussions (FGDs) with lecturers, general practitioners in primary health care centers, and managers from the district health care. ${ }^{19}$ In this study, the qualitative results were combined with an extensive literature review to produce the set of guidelines called, IPE-COM (Interprofessional Education in Community-based Learning), which details three phases of learning design (Table 1). 5,7,23,25 This IPE-COM paradigm was different from the previous literature in the ways students started to

Table I IPE-COM learning design adapted for Indonesia

\begin{tabular}{|l|l|l|}
\hline Phase & Instruction & Activities \\
\hline First & IPE socialization and training & $\begin{array}{l}\text { Students and supervisors trained about IPE and community } \\
\text { development in health services. }\end{array}$ \\
\hline Second & $\begin{array}{l}\text { Implementation IPE-CBL with 7 steps: } \\
\text { I. Identify the stakeholders in the community } \\
\text { 2. Approach the community } \\
\text { 3. Assess the needs of local communities } \\
\text { 4. Planning project in each perspective. } \\
\text { 5. Focus project } \\
\text { 6. Implementation of the project } \\
\text { 7. Reflection }\end{array}$ & Students engaged in community in order to do health projects \\
\hline Third & Evaluation by IPE students' report & Students reported their learning experiences to supervisors \\
\hline
\end{tabular}


engage with the community in a local cultural approach. ${ }^{19}$ The IPE-COM paradigm has not yet been tested and published. Therefore, we aimed to conduct a pilot study of IPECOM for medical and midwifery students and evaluated it with the previously validated Intercollaborator Assessment Rubric. $^{8}$

\section{Methods \\ Research design}

The design of this study is a one-group pre-experimental study with a pre- and post-test. The treatment group included medical and midwifery students who engaged in IPE-COM course. Data were collected twice: before and after the intervention. Before intervention (pre-test), all participants were assessed for IPE competencies. At the end of the intervention, all participants were assessed again in the same competencies to provide post-test data.

\section{Participants}

Participants were selected purposively with a total sampling of 15 medical students and 19 midwifery students. The participants in this study followed the public health clinical rotation in the obstetric community at two primary health care centers (Puskesmas) in Surakarta, Central Java, from December 2015 to January 2016. All participants were randomly divided into nine groups that consisted of at least one medical student and two midwifery students. Each group was assigned to provide health prevention and promotion for one family who had maternal and child health risks. Each group defined their own strategies in delivering their task for the family. We had previously trained the students with collaborative interprofessional learning during the first phase of this study (introduction of IPE).

\section{IPE community-based learning (IPE-COM) design}

There were three phases in this learning design, namely:

\section{(a) First phase: Introduction of IPE-COM}

During the first week of the course, students and supervisors were given detailed explanations about IPE and the structure of the IPE-COM course in Sebelas Maret University. Skill training, such as leadership building, interprofessional communication, team management, and reflection skills, was conducted for students. Additionally,
IPE skill training, involving assessments of students and facilitating in IPE, was delivered to the supervisors.

(b) Second phase: Implementation of IPE-COM

All students, who were engaged in the implementation of IPE-COM, were assigned to a community health center for three weeks. There were seven steps that were performed by the supervised students to implement IPE:

1. Identify the stakeholders in the community

- The first act of IPE team was to identify persons who have a significant role in the community, such us head of community health center, leader of health care provider, district leader, religious leader, etc.

2. Approach in the community

- To be in contact with the community, the IPE team need to consider how to approach the community. The team should be considerate about the culture and local wisdom in order to communicate and invite the community into health care projects.

3. Assess the needs of local communities

- A comprehensive need assessment was conducted to catch the gap of health condition and perception within the community. The IPE team would perform assessment in the holistic aspects of community, which are biological, psychological, social, cultural, religion, environmental, family safety, and community regulation (local rules).

4. Plan project in each perspective.

- After the IPE team assessed the community's needs, the team would arrange a list of problems derived from the identified gap of health status. The identification of problems should be based on all perspectives and by both professions (medical and midwifery). Then, the IPE team made some project plans in order to solve the problems. Project plans should gather necessary knowledge and skills of all team members.

5. Focus project

- To prioritize was crucial to focus the project plans, given the limited time and resources available. The team should be able to concentrate on specific goals for the planned family or community project.

6. Implementation of the project

- The IPE team did their project that lasted for two to three weeks. 


\section{Reflection}

- Reflection means evaluation of all the processes. During this step, the IPE team did not only discuss about the project, but they also reflected on the interprofessional collaboration and communication. For example, the students might describe what they have accomplished, the plans that have not been completed, their limitations, and their thoughts for future recommendation.

Additionally, the project for this IPE-COM involved comprehensive family medicine. In this pilot project, each group was engaged in assessing one family for maternal and child health risks. The students assessed antenatal patients with specific diseases, such as anemia, gestational hypertension, low intake protein, and poor hygiene. Then, the students planned promotive and preventive initiatives to provide intervention and remedy for those diseases. The students did not only help the patients but also treated and educated the family.

(c) Third phase: Reporting IPE

By the end of the course, students created reports by documenting and reflecting about their activities during IPE community-based learning.

\section{Instrument}

In order to assess student's IPE competencies, we used the Interprofessional Collaborator Assessment Rubric or ICAR that was adapted from Curran et al. ${ }^{8}$ We validated the instrument by checking the translation (English-Indonesian), and back translation (Indonesian-English) with the formal English translator unit of University of Sebelas Maret, and then tested it with 30 health professional teachers. We used the Pearson correlation and alpha cronbach tests for reliability measurements. There were 2 items dropped because the results were less than 0.6 in the domains of collaboration and communication competences. The alpha Cronbach test for this validated instrument was 0.87 , which means high reliability. ${ }^{9}$ Then, we trained the teachers on how to use the instrument in the first phase (introduction of IPE) in this study. In the process, we discussed with the teachers how to observe and interpret each of the items of the ICAR, which had already been translated into Bahasa Indonesia.

There were six IPE competence measures in the assessment: (1) communication, (2) collaboration, (3) roles and responsibilities, (4) team functioning, (5) collaborative patient-centered approach, and (6) conflict management. Interrater reliability was measured to be inter-rater agreement between supervisors.

\section{Data collection}

The supervisors were two medical doctors and two midwives who were recruited by the researchers in this study. They assessed the IPE competencies by direct observation in student activities before and after the IPE learning. Each group was observed by one medical doctor and one midwife who were randomly assigned. The first family visit was done by students and supervisors as a pre-test for the student. After several family visits and when the student finished the project intervention, the last family visit was repeated by the students and supervisors as the post-test for the student. Collecting measurements of the student's IPE competencies was conducted by the supervisors.

\section{Analysis of results}

We analyzed the results of the IPE assessment rubric using paired $t$-test non paramatric (Wilcoxon test) analysis with the non-parametric Wilcoxon test with a value of $95 \%$ confidence interval $(\mathrm{CI})(P<0.05)$. The Wilcoxon test was used because the result of ICAR was ordinal (nonparametric variables). The analysis was continued with tests of significant correlations with an Effect Size test. ${ }^{9}$

\section{Research ethics}

This study has been approved by the Bioethics Committee, Faculty of Medicine, Universitas Sebelas Maret (No: 54/I/ HREC/2016). Before the data collection began, all of the medical and midwifery students had read and signed an informed consent form. The patients and their family who were also involved in the health project intervention (focused on promotive and prevention) were also asked for informed consent before they got the intervention. The IPE team provided informed consent to them as ethical clearance.

\section{Results}

\section{Characteristics of participants}

Thirty-four students of medical and midwifery courses were divided into nine groups. Each group consisted of medical students and midwives. Participants' characteristics are presented in Table 2. 
Table 2 Characteristics of participants

\begin{tabular}{|l|l|}
\hline Characteristics & Frequency \\
\hline $\begin{array}{l}\text { Gender } \\
\text { a. Male } \\
\text { b. Female }\end{array}$ & 6 people (18\%) \\
\hline $\begin{array}{l}\text { Profession } \\
\text { a. Midwife } \\
\text { b. Doctor }\end{array}$ & \\
\hline $\begin{array}{l}\text { Supervisor } \\
\text { a. Doctor }\end{array}$ & 19 people (56\%) \\
b. Midwife & 15 people (44\%) \\
\hline $\begin{array}{l}\text { Supervisor educational background } \\
\text { a. Master }\end{array}$ & 2 people (50\%) \\
b. Bachelor degree/profession & 2 people (50\%) \\
c. 3-Year diploma & \\
\hline
\end{tabular}

\section{Interrater reliability test of ICAR instruments}

Based on the inter-rater reliability test data in Table 2, it can be concluded that the four raters had a close inter-rater agreement $(>0.80)$. There was only one value of 0.738 in the pre-test involving the competency of roles and responsibilities. Based on these results, the ICAR instrument could be used by all raters to assess the attainment of IPE competencies in the pre- and post-test.

Based on Table 4, the six domains of IPE competence perceptions measured in all participants had a significant difference between the measurements before and after the IPE intervention $(P<0.05)$. This result shows there was an increase in the competences in all six IPE competencies after the intervention was conducted with all participants.

Table 3 Data on inter-rater reliability test

\begin{tabular}{|l|l|l|}
\hline \multirow{2}{*}{ Competency } & \multicolumn{2}{|l|}{$\begin{array}{l}\text { Result of intraclass } \\
\text { correlation* }\end{array}$} \\
\cline { 2 - 3 } & $\begin{array}{l}\text { Data pre- } \\
\text { test }\end{array}$ & $\begin{array}{l}\text { Data post- } \\
\text { test }\end{array}$ \\
\hline Communication & 0.848 & 0.853 \\
Collaboration & 0.867 & 0.870 \\
Role and responsibility & $0.738^{* *}$ & 0.827 \\
Collaborative patient-centered approach & 0.823 & 0.887 \\
Team functioning & 0.911 & 0.815 \\
Conflict management/resolution & 0.847 & 0.898 \\
\hline
\end{tabular}

Notes: $*$ Intraclass correlation $>0.80=$ high stability. $* *$ Intraclass correlation $0.50-0.80=$ moderate stability.

\section{Pre- and post-test results}

Based on the interpretation of effect size by Cohen, ${ }^{9}$ the competence of communication, collaboration, roles and responsibilities, functioning team, and conflict management had a strong effect $(\mathrm{d}>1.00)$; thus, it is assumed that the IPE interventions had a strong effect on the five competencies, while the competency of a collaborative approach centered on the patient and family had a moderate effect ( $\mathrm{d}=0.51$ to 1.00$)$; thus, it is assumed that the effect of the IPE intervention had only a "moderate" impact to improve the competency.

Based on Figure 1, it appears that the mean value of the medical students' competency perception achievement was higher than that of the midwifery students at the time of measurement. However, both professions showed an increase in their scores between the pre-test and post-test.

\section{Discussion}

Community-based learning or community-based education is a comprehensive method to apply and practice the IPE knowledge, skills, and attitudes of health profession students. In addition to clinical learning, the community-based learning is also an experiential vehicle for the real world of work (real settings). Therefore, it becomes an important learning experience that should be obtained by students, including how to better understand the influence of the socio-cultural, economical, and epidemiological challenges of a community, population demographics, and government policies regarding the health of individuals, families, and communities. ${ }^{21}$ Learning communities also train students to be more able to effectively collaborate, both in better collaboration with the community and also greater competency with other health care professionals. ${ }^{4}$ Therefore, we recommend the application of appropriate community learning as well as community-based interprofessional teaching methods for IPE curriculum.

In general, the purpose of the IPE intervention is to enable the students to gain learning experiences in the community by doing collaborative projects with health care professionals. This study depicted that the participation of two different health professions students enabled more comprehensive approach to solve personal and community health problems. It is argued here that a good collaboration of a health profession team will support the realization of improving the quality of health services. With this purpose, community-based IPE should not only aim to handle a public health problem but also to help with the implementation of government programs. ${ }^{5,29}$ 
Table 4 Wilcoxon test result

\begin{tabular}{|l|l|l|l|l|l|l|l|l|l|l|l|}
\hline \multirow{2}{*}{ Competency } & \multicolumn{3}{|l|}{ Pre-test } & \multicolumn{3}{|l|}{ Post-test } & \multirow{2}{*}{ Value P* } & \multirow{2}{*}{ Effect size } \\
\cline { 2 - 10 } & Min & Max & Median & SD & Min & Max & Median & SD & \\
\hline I. Communication & 2.29 & 3.16 & 2.87 & 0.22 & 2.79 & 3.33 & 3.04 & 0.20 & 0.00 & $1.33^{* *}$ \\
2. Collaboration & 2.43 & 3.25 & 2.68 & 0.29 & 2.68 & 3.50 & 3.06 & 0.26 & 0.00 & $1.37^{* *}$ \\
3. Role and responsibility & 2.03 & 3.46 & 2.62 & 0.28 & 2.75 & 3.46 & 3.05 & 0.16 & 0.00 & $1.88^{* *}$ \\
4. Collaborative patient-centered approach & 2.06 & 3.00 & 2.50 & 0.25 & 2.25 & 3.25 & 2.87 & 0.30 & 0.00 & $0.86^{* * *}$ \\
5. Team Functioning & 1.75 & 3.20 & 2.50 & 0.31 & 2.90 & 3.65 & 3.20 & 0.20 & 0.00 & $2.76^{* *}$ \\
6. Conflict management/resolution & 2.06 & 3.00 & 2.59 & 0.25 & 2.62 & 3.68 & 3.25 & 0.31 & 0.00 & $2.45^{* *}$ \\
\hline
\end{tabular}

Notes: *Value $P<0.05$ meaning there is a statistically significant difference. **Effect size $d>1.00$ meaning the intervention effect is statistically strong. $* * *$ Effect size $0.5 \mathrm{I} \leq \mathrm{d} \leq \mathrm{I} .00$ meaning the intervention effect is statistically moderate.

In addition, the community-learning program that was piloted in this study is one example of experimental learning, where the field experiences become constructive building blocks of students' knowledge, skills, and attitude. Development of new methods of teaching IPE should be collaboratively developed and should consider to focus on work-based learning in the community where students will gain learning experiences by engaging with the real population setting. ${ }^{11}$

The results of the increased value of IPE collaborative competency perceptions in this study showed that the intervention process during the IPE community-based learning was effective and had a significant impact on increasing students' IPE competency achievement based on the supervisors' perceptions. There were three major processes designed in the IPE learning intervention in this study: the introduction, implementation and reflection, and evaluation.

In this study, the learning process and success of IPE intervention were measured at the level of supervisors' perceptions. This measurement needs to be taken to determine the IPE competency achievement in students by developing an appropriate assessment blueprint so that it can properly assess changes in attitudes, skills and IPE knowledge of students. However, in this study, the level of perception obtained from the raters who performed direct observation provided clear indication that the students had engaged in IPE learning experience capable of changing collaborative perspectives with other health professions, from before applying new knowledge, through making joint projects and finally after implementation, performing reflection and evaluation.

This study showed that health care teams and comprehensive care are important in improving the quality of care. In the first phase, this study emphasized and exposed the students to see health perspectives in an interprofessional way. Next, they learned how to provide treatment for a disease by facing non-medical aspects that can affect the quality of health. In the process, social hierarchy and barriers with other professionals were expected not to pose any problem for communication and team performance. ${ }^{1}$

Students were also trained about team management, project planning, and communication between professions at the introduction stage. According to Barr et $\mathrm{al}^{3}$ and Kahaleh et al, ${ }^{14}$ team building and establishing good communication must be performed from the beginning of health care collaboration. Building a collaborative team of health professionals needs to focus on individual aspects of each profession, including behaviors, personal feelings, internalized norms, beliefs, and self-concepts. ${ }^{26}$

At the second phase, the students were guided using the aforementioned seven-step implementation of the IPECOM curriculum. The seven steps helped students to introduce themselves to the community, interact with the community, conduct a community assessment, create health project planning, implementation, make a conclusion after reflecting on the activities, and have a final evaluation. According to recent research, Foroushani et a ${ }^{10}$ suggested that the initial approach process and the early involvement acts in the community would determine how people in the community receive the health care team. The process of self-introduction, the provision of health care purposes, and treatment methods are important aspects to consider before IPE team can be delivered. These essential components are also important aspects of the safety of patients. ${ }^{6,12}$

In the phase of project planning, focusing and project implementation are steps that assist students in good project management. Interprofessional group discussion was important in providing perceptions, suggestions, and key understanding from other professions about how their 


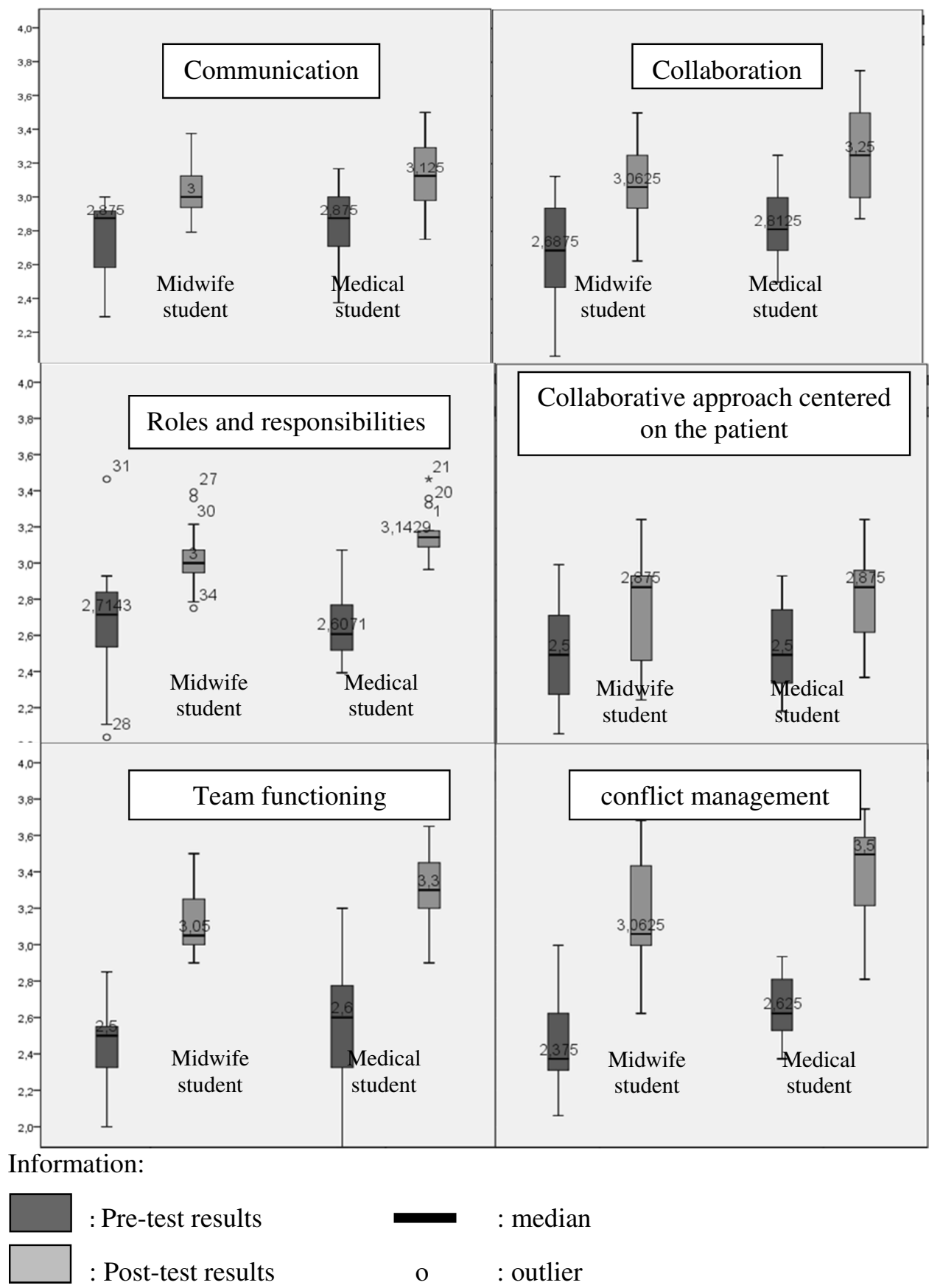

Figure I Difference on collaborative competency perception value in each profession.

roles, opinions, and methods for conflict management can create a core resolution group for any challenges associated with health care services. ${ }^{13}$

There were five among six IPE competencies in the results of this study which had a mean value above three in the post-test. These results indicated that students reached the stage of "competent", compared to pre-test results, which showed the level of the five competencies as "developing". 8 The competencies mentioned were communication, collaboration, roles and responsibilities, functioning team, and conflict management. Thus, this study demonstrated that IPE learning interventions can help to increase the levels of core competency of IPE students.

The impact of interventions, that had a moderate effect, was related to the competence of ethics, which involves a collaborative approach that concentrates on the patient or family (patient-centeredness). Some studies similarly have 
also mentioned that ethical issues are a challenge to the implementation of IPE, such as aspects of patient safety, considerations about patient comfort with a variety of health workers who treat them, and how patients are treated as human beings. ${ }^{1,20}$ In this study, the ethical aspects became challenges for students to be competent as a provider of patient-centered health care. Our recommendations for future study involve how IPE curriculum should emphasize about collaborative patient-centered care for both undergraduate and postgraduate health profession educations. In this study, the students only had short-term experiences in working collaboratively in the health prevention and promotion sectors. Therefore, collaborative patient-centered care might be more challenging and not appear to be as significant, because the students had little to no experience in real patient care.

The highest achievement of competency occurred in the competency of a "functioning team". This achievement was made possible due to the collaborative process, involving the very high intensity and frequency of inter-professionals engagement, to meet and discuss the health projects. This result was evident at every stage of the IPE learning between the medical students and midwifery students that always met regularly (for 3 weeks) while they intensively conducted the projects together. Similar results were also revealed in the research by Sevin et al, ${ }^{25}$ Saxell et al, ${ }^{23}$ and Zanoti et $\mathrm{al}^{29}$ that found the intensity of interprofessional discussion and communication in a course or learning activity specifically designed with the concepts of IPE would raise awareness and create a more conducive environment for good teamwork in patient health care.

The second highest achievement of IPE competencies of conflict management and resolution becomes important to address the challenges and barriers to the implementation of the curriculum related to the IPE in the differing paradigms of each profession. Conflicts seen in this study involved challenges to honor the perspectives of other professions, difficulties in listening to others' involvement in the discussions, and a lack of resolution strategies in the event of disagreements. In this study, each profession had to understand and appreciate the role and responsibilities of the other profession, so it would be easier to collaborate in conflict management. Another aspect that was also supportive was that the students were able to manage conflict, for example, in their improvement of the communication competency where students were rated "respectful" toward interprofessional communication and how to communicate well, demonstrating core competencies supported by communication training at the stage of introduction.

This study had some limitations during the process in the field. First, this study did not have a control group to serve as the comparison group. This approach was because of the short period of the study, the limited number of medical students in public health clinical rotation, as well as midwifery students in the obstetric community phase. Second, IPE competency assessment by observation is actually an effective way to see the changes and the achievement of student competency. However, in this study, the change could not be observed in the mid-time of the study. This approach was because the researchers had difficulty to adjust the times of the assessment. Finally, the time of this study was adjusted with the students' community placement at the health centers, to only three weeks; thus, the time was perceived lacking for giving extended IPE learning intervention and seeing longterm changes in students' competency.

\section{Conclusion}

The IPE-COM learning design in this study was demonstrated to have positive impacts to increase the objectives of IPE's core competencies, which were tested by the ICAR instrument: communication, collaboration, roles and responsibilities, team functioning, and conflict management for the medical and midwifery undergraduate students. The IPE-COM approach has a strong impact on the achievement of the "functioning team" and a moderate impact on the competency of "patient-centered collaborative approach". Therefore, we recommend medical educators to use IPE-COM learning designs for future research and skill training in an IPE learning context.

\section{Acknowledgment}

The authors would like to acknowledge the IPE team of Faculty of Medicine Universitas Sebelas Maret, Dr. Eti Poncorini Pamungkasari, Dr., MPd; Ari Probandari, Dr., MPH, PhD; Sri Anggarini, SSIT, MKes; Bulan Kakanita Hermasari, Dr; and Zulaika Nur Afifah, Dr., MKes and the students of Faculty of Medicine Universitas Sebelas Maret who have participated actively and enthusiastically in helping the research process.

\section{Disclosure}

The authors report no conflicts of interest in this work. 


\section{References}

1. Altin SV, Tebest R, Freimuth SK, Redaelli M, Stock S. Barriers in the implementation of interprofessional continuing education programs a qualitative study from Germany. BMC Med Educ. 2014;14:227. doi:10.1186/1472-6920-14-227

2. Barr H. An anatomy of continuing interprofessional education. J Contin Educ Health Prof. 2009;29(3):147-150. doi:10.1002/chp.20027

3. Barr H, Koppel I, Reeves S, et al. Effective Interprofessional Education: Argument, Assumption and Evidence. Oxford: Blackwell Publishing Ltd; 2005.

4. Brennan CW, Olds DM, Dolansky M, Estrada CA, Patrician PA. Learning by doing: observing an interprofessional process as an interprofessional team. $J$ Interprof Care. 2014;28(3):249-251. doi:10.3109/13561820.2013.838750

5. Bridge D, Davidson R, Odegard PS, Maki I, Tomkowiak J. Interprofessional collaboration: three best practice models of interprofessional education. Med Educ Online. 2011;16:6035. doi:10.3402/meo. v16i0.6035

6. Buring SM, Bhusan A, Broseker A, et al. Interprofessional education: definitions, student competencies, and guidelines for implementation. Am J Pharm Educ. 2009;73(4):59. Article 59.

7. Cullen L, Fraser D, Symonds I. Strategies for interprofessional education: the Interprofessional Team Objective Structured Clinical Examination for midwifery and medical students. Nurse Education Today. 2003;23(6):427-433.

8. Curran V, Hollet A, Casimiro L, et al. Development and validation of the interprofessional collaborator assessment rubric (ICAR). J Interprof Care. 2011;25:339-344. doi:10.3109/13561820.2011.589542

9. Cohen L, Manion L, Morrison K. Research Methods in EducationSixth Edition. New York: Routledge; 2007.

10. Foroushani PS, Travagliat J, Debono D, Braithwaite J. Implementing strategies in consumer and community engagement in health care: results of a large-scale, scoping meta-review. BMC Health Serv Res. 2014;14:402. doi:10.1186/1472-6963-14-402

11. Hall LW, Zierler BK. Interprofessional Education and Practice Guide No. 1 : developing faculty to effectively facilitate interprofessional education. $J$ Interprof Care. 2015;29(1):3-7. doi:10.3109/13561820.2014.937483

12. Hallin K, Henriksson P, Dalen N, Kiessling A. Effects of interprofessional education on patient perceived quality of care. Med Teach. 2011;33(1):e22-e26. doi:10.3109/0142159X.2011.530314

13. Interprofessional Education Collaborative Expert Panel. Core Competencies for Interprofessional Collaborative Practice: Report of an Expert Panel. Washington (DC): Interprofessional Education Collaborative; 2011.

14. Kahaleh AA, Danielson J, Franson KL, et al. An interprofessional education panel on development, implementation, and assessment strategies. Am J Pharm Educ. 2015;79(6):78. Article 78. doi:10.5688/ ajpe79799
15. Ministry of Health of Indonesia. Kinerja Dua Tahun Kementerian Kesehatan Republik Indonesia. Jakarta: Kementerian Kesehatan Republik Indonesia; 2011.

16. Ministry of Health of Indonesia. Riset Dasar Kesehatan 2013. Jakarta: Badan Penelitian dan Pengembangan KesehatanKementerian Kesehatan RI; 2014.

17. Morrison S. Working together: why bother with collaboration? Work Bas Learn Prim Care. 2007;5:65-70.

18. Olenick M, Allen LR, Smego RA. Interprofessional education: a concept analysis. Adv Med Educ Pract. 2010;1:75-84.

19. Pamunkasari EP, Probandari AN, Anggarini S, Randita ABT Pengembangan Model Pembelajaran Interprofessional Education (IPE) Mahsiswa Kedokteran dan Kebidanan. Universitas Sebelas Maret research Grant Report; 2015.

20. Rathbone AP, Mansoor SM, Krass I, Hamrosi K, Aslani P. Qualitative study to conceptualise a model of interprofessional collaboration between pharmacists and general practitioners to support patients' adherence to medication. BMJ Open. 2016;6:e010488. doi:10.1136/bmjopen-2015-010488

21. Robert KB. Educational principles of community-based education. Pediatrics. 1996;98(6 Pt 2):1259-1292.

22. Rosenfield D, Oandasan I, Reeves S. Perceptions versus reality: a qualitative study of students' expectations and experiences of interprofessional education. Med Educ. 2011;45:471-477. doi:10.1111/ med.2011.45.issue-5

23. Saxell L, Harris S, Elarar L. The collaboration for maternal and newborn health: interprofessional maternity care education for medical, midwifery, and nursing students. J Midwifery Womens Health. 2009;54:314-320. doi:10.1016/j.jmwh.2009.03.017

24. Sargeant J. Theories to aid understanding and implementation of interprofessional education. J Contin Educ Health Prof. 2009;29 (3):178-184. doi:10.1002/chp.20033

25. Sevin AM, Hale KM, Brown NV, McAuley JW. Assessing interprofessional education collaborative competencies in service-learning course. Am J Pharm Educ. 2016;80(2):32. Article 32. doi:10.5688/ ajpe 80232

26. Weiss D, Tilin F, Morgan M. The Interprofessional Health Care Team: Leadership and Development. Massachusetts: Jones \& Bartlett Learning; 2014.

27. WHO. Interprofessional colaborative practice in primary health care. Nursing and midwifery perspective. Six case studies. Hum Resour Health Obs. 2013;13:4.

28. WHO. (2014). The Millenium Development Goals Report 2014. New York: WHO

29. Zanotti R, Sartor G, Canova C. Effectiveness of interprofessional educationby on-field training for medical students, with a pre-post design. BMC Med Educ. 2015;15:121. doi:10.1186/s12909-0150409-z
Journal of Multidisciplinary Healthcare

\section{Publish your work in this journal}

The Journal of Multidisciplinary Healthcare is an international, peerreviewed open-access journal that aims to represent and publish research in healthcare areas delivered by practitioners of different disciplines. This includes studies and reviews conducted by multidisciplinary teams as well as research which evaluates the results or conduct of such teams or healthcare processes in general. The journal covers a very wide range of areas and welcomes submissions from practitioners at all levels, from all over the world. The manuscript management system is completely online and includes a very quick and fair peer-review system. Visit http://www.dovepress.com/testimonials. php to read real quotes from published authors. 